\title{
Higher visceral fat area increases the risk of vitamin $D$ insufficiency and deficiency in Chinese adults
}

\author{
Meilin Zhang ${ }^{1}$, Ping Li ${ }^{1}$, Yufeng Zhu ${ }^{1}$, Hong Chang ${ }^{1,2}$, Xuan Wang ${ }^{1}$, Weiqiao Liu ${ }^{3}$, Yuwen Zhang ${ }^{3}$ \\ and Guowei Huang ${ }^{1 *}$
}

\begin{abstract}
Background: Visceral fat area (VFA), a novel sex-specific index for visceral fat obesity (VFO) might play a major role in the development of vitamin D deficiency. However, the association between VFA and vitamin D insufficiency and deficiency in Chinese population is less clear. The aim of this study was to explore the population-level association between VFA and vitamin D insufficiency and deficiency among Chinese men and women.
\end{abstract}

Methods: This cross-sectional study involved 1105 adults aged 20-70 years living in Tianjin who were randomly selected and medically examined. All subjects underwent the bioelectrical impedance analysis (BIA) method to estimate the VFA. Serum 25-hydroxyvitamin $\mathrm{D}_{3}\left(25(\mathrm{OH}) \mathrm{D}_{3}\right.$ ) level was assayed by the high-performance liquid chromatography (HPLC) method and defined insufficiency and deficiency following recommended cutoffs. The association between VFA and vitamin $D$ insufficiency and deficiency was estimated using binary regression analysis.

Results: The total prevalence of vitamin D insufficiency $\left(25(\mathrm{OH}) \mathrm{D}_{3}: 20-29 \mu \mathrm{g} / \mathrm{L}\right)$ and deficiency $\left(25(\mathrm{OH}) \mathrm{D}_{3}<20 \mu \mathrm{g} / \mathrm{L}\right)$ were $26.60 \%$ and $24.89 \%$, respectively. Significant negative association was observed for VFA with serum $25(\mathrm{OH}) D_{3}$ levels in men and pre-menopausal women $(P<0.05)$, not in post-menopausal women $(P>0.05)$. Moreover, increased VFA was observed to be associated with higher vitamin $D$ insufficiency or deficiency risk with a positive dose-response trend ( $P$ for trend $<0.001$ ). As compared to individuals with the lowest VFA, those who had the highest VFA were at 4.9-fold risk of vitamin D insufficiency and deficiency [95\% confidence interval (95\% Cl): 1.792-13.365] in men and 1.8-fold risk of vitamin D insufficiency and deficiency (95\% Cl: 1.051-3.210) in pre-menopausal women, but not in post-menopausal women [odds ratio (OR) (95\% Cl): 2.326(0.903-5.991)].

Conclusions: These results suggest that higher VFA increases the risk of vitamin D insufficiency and deficiency in men and pre-menopausal women, but not in post-menopausal women. VFA is a better and convenience surrogate marker for visceral adipose measurement and could be used in identifying the risk of vitamin D insufficiency and deficiency in routine health examination.

Keywords: Visceral fat area, 25-hydroxyvitamin $\mathrm{D}_{3}$, Vitamin D deficiency, Visceral fat obesity

\section{Background}

Vitamin D deficiency is now being recognized as a major global public health problem [1-3]. Approximately 1 billion people worldwide have vitamin D deficiency [4]. In China, vitamin D deficiency is common in the middleaged and elderly population. The prevalence of vitamin D

\footnotetext{
* Correspondence: tjgwhuang@126.com

${ }^{1}$ Department of Nutrition and Food Science, School of Public Health, Tianjin Medical University, Tianjin 300070, China

Full list of author information is available at the end of the article
}

deficiency was $69.2 \%$ in Beijing and Shanghai [5], and the prevalence of vitamin D deficiency was $75.2 \%$ in the northwestern inland of China [6].

Traditional roles of vitamin D lie within the musculoskeletal system, maintaining calcium homoeostasis and bone metabolism. In recent years, new functional roles of vitamin D have emerged linking the fat-soluble vitamin to various non-communicable diseases. The consequences of vitamin D deficiency include poor bone development and health as well as increase risk of many chronic diseases 
including insulin resistance, diabetes and cardiovascular disease [7], which is also commonly linked with obesity and visceral fat obesity (VFO).

Anthropometric indices such as body mass index (BMI) have been used widely in the previous studies examining the relationship between obesity and vitamin $\mathrm{D}[8,9]$. In particular, VFO compared with overall obesity might play a major role in the development of vitamin D deficiency. Therefore, estimating visceral fat accumulation is important to identify individuals at high risk for vitamin D deficiency. Their inability to distinguish visceral fat precludes their ability to accurately assess abdominal fat accumulation. Because fat accumulation in different areas represents different risk for metabolic disorders and visceral adipose tissue may be unique [10], we sought to evaluate visceral fat. Conventionally, the simplest and most widely used method of assessing visceral fat accumulation is measuring the waist circumference (WC) [11]. Although WC is recognized as an independent and powerful risk factor for vitamin $\mathrm{D}$ deficiency, there might be substantial variations in the visceral fat amount among persons with a similar WC because WC itself performs poorly in discriminating between visceral and subcutaneous fat. Therefore, it is possible that subjects with a normal WC may be more prone to vitamin $\mathrm{D}$ deficiency if they have centrally located body fat. Many sophisticated methods such as dual-energy $x$-ray absorptiometry (DEXA), computed tomography (CT) and magnetic resonance imaging (MRI) have been developed to provide more precise estimates of the location and amount of adipose tissue in various body regions [12]. However, DEXA, CT and MRI are impractical for screening general population, since they require expensive and specialized equipment, and exposure to radiation. Studies have compared the general usage of bioelectrical impedance analysis (BIA) with one of these more established methods (CT, MRI or DEXA). BIA has been shown to accurately predict DXEAderived percentage body fat (PBF) in the Chinese population $(\mathrm{r}=0.89, P<0.05)$ [13]. VFA measured by BIA correlated significantly with that acquired by CT $(r=0.992$ for VFA, using data from the Biospace of 332 patients) [14]. Although BIA is not considered a "gold standard", BIA has been considered a valid alternative for measuring body fat in large studies or clinical practice [15], which has also been validated against reference methods [13, 14].

Visceral fat area (VFA), a novel sex-specific index for VFO, has been proposed recently. One study has examined the association of 25-hydroxyvitamin $\mathrm{D}_{3}(25(\mathrm{OH})$ $\mathrm{D}_{3}$ ) level and VFO in Chinese men and discovered serum $25(\mathrm{OH}) \mathrm{D}_{3}$ levels were inversely associated with VFA [16]. To our knowledge, serum $25(\mathrm{OH}) \mathrm{D}_{3}$ levels and the distribution of abdominal fat are known to be distinctive between men and women [17-19], as well as between pre-memopausal and post-memopausal women. However, the significance of association between VFA and vitamin $\mathrm{D}$ insufficiency and deficiency in the Chinese population is less clear. In the present study, a simple method for the measurement of visceral fat accumulation using BIA [20] was performed to explore the population-level association between VFA and vitamin D insufficiency and deficiency in Chinese men and women.

\section{Methods}

\section{Subjects}

This overall population includes 1130 subjects aged 2070 years coming to the Health Examination Center of Heping District in Tianjin, China for routine health checkup during November to December in 2013, were enrolled. 1105 subjects were included for analysis according to the following inclusion and exclusion criteria. Inclusion criteria were as follows: 1) aged 20-70 years, 2) written informed consent, 3) willingness to take part in the examination and willingness to provide blood samples. Exclusion criteria were as follows: 1$)$ individuals whose medical data were incomplete $(n=10), 2)$ individuals who took diuretics $(n=3), 3)$ individuals who undergone hormone replacement therapy $(n=2), 4)$ individuals with chronic kidney disease $(n=3), 5)$ individuals with presence of tumor, infectious diseases or psychiatric disease $(n=3), 6)$ individuals with severe disability or occurrence of bone fracture within the past six months $(n=2)$; 7) individuals who have had stents or with history of cardiovascular disease $(n=2)$.

The study was conducted in accordance with the Declaration of Helsinki and approved by the Ethics Committee of Tianjin Medical University. All study participants provided written informed consent prior to enrollment.

\section{Body fat measurements}

Body fat measurements, consisting of BMI, WC, waist-to-hip ratio (WHR), fat mass (FM), free fat mass (FFM), PBF and VFA were estimated by the BIA method (Inbody 720 Body Composition Analyzer, Korean).

\section{Anthropometric and biochemical assessments}

Systolic blood pressure (SBP) and diastolic blood pressure (DBP) were measured by trained nurses with a mercury sphygmomanometer on the right arm of the subjects in a comfortable siting position after 5 -min rest. After 10-h overnight fasting, blood samples were collected from all subjects to measure serum $25(\mathrm{OH}) \mathrm{D}_{3}$ levels as well as other biochemical parameters. Fasting plasma glucose (FPG) was measured by the glucose oxidase method. Lipid profiles, including total cholesterol (TC) and triglycerides (TG) were determined using the standard enzymatic 
methods, while low-density lipoprotein cholesterol (LDL-c) and high-density lipoprotein cholesterol (HDL-c) were determined by the direct assay method. All of the above measurements were carried out on a Hitachi 7600-120 auto-analyzer (Tokyo, Japan). Total serum $25(\mathrm{OH}) \mathrm{D}_{3}$ level was assayed by the high-performance liquid chromatography (HPLC) method.

\section{Definition of terms}

Obesity was defined as a BMI value exceeding $28 \mathrm{~kg} / \mathrm{m}^{2}$ [21]. VFO was defined as $W C \geq 90 \mathrm{~cm}$ for men or $\geq 80 \mathrm{~cm}$ for women. Or VFO was defined as a VFA exceeding $130 \mathrm{~cm}^{2}$ in men and $100 \mathrm{~cm}^{2}$ in women [22]. Vitamin D status was defined as follows: A serum level of $25(\mathrm{OH})$ $\mathrm{D}_{3}<20 \mu \mathrm{g} / \mathrm{L}$ is considered to be vitamin $\mathrm{D}$ deficiency, whereas a level $20-29 \mu \mathrm{g} / \mathrm{L}$ is insufficient, and to maximize vitamin D's effect for health, $25(\mathrm{OH}) \mathrm{D}_{3}$ should be $\geq 30 \mu \mathrm{g} / \mathrm{L}$ [23].

\section{Lifestyle factors}

Smoking behavior, drinking behavior, current daily time spent outdoors, physical activity, menopausal status and vitamin D supplement intake were collected using self-administered questionnaires. The current time spent outdoors (h/d) was used as an indicator for sunshine time. A woman was considered post-menopausal if she reported menses had ceased for 1 year or more, and age at menopause was self-reported as previously reported.

\section{Statistical analysis}

According to the sample size, a normal distribution was tested by the Kolmogorov-Smirnov test with the Lilliefors correction for men and women. Normally distributed variables were presented as the mean \pm standard deviation, whereas skewed variables were presented as the median (interquartile range). Because of significant sex difference in the amount of total body fat, fat distribution and lifestyle factors, we performed sex-stratified analyses. For continuous variables, the independent sample $t$-test and the Wilcoxon rank-sum test were used for between-group comparisons of normally distributed and skewed data, respectively. Comparative analyses of categorical variables were carried out using a Chi-square test. Each participant was categorized into one of four subgroups depending on their total VFA. To compare variables between these subgroups, one-way analysis of variance (ANOVA) followed by Scheffé post hoc test or Mann-Whitney $U$ test were used where appropriate. Partial correlation analyses between serum $25(\mathrm{OH}) \mathrm{D}_{3}$ and other variables were adjusted for age. Binary logistic regression was performed to examine the association between body fatness indices and vitamin D insufficiency and deficiency. Data were analyzed using SPSS (Chicago, IL) version 13.0 statistical software.
$P$ value less than 0.05 was considered to indicate a statistically significant difference.

\section{Results}

\section{Descriptive characteristics of the study population}

The characteristics of the study population were shown in Table 1. Overall, the prevalence of visceral fat obesity was higher than obesity. It was showed that the men had a higher age, WHR, BMI, WC, FM, VFA, FFM, SBP, DBP, sunshine time, higher levels of TG, LDL-c, FPG and lower levels of PBF, 25(OH) $D_{3}$ and HDL-c. But there was no difference in $\mathrm{TC}$ and vitamin $\mathrm{D}$ supplementation intake between the men and women. The prevalence of obesity, visceral fat obesity and vitamin D deficiency in men was higher than in the women, whereas the prevalence of vitamin D insufficiency in men was lower than in the women.

\section{Characteristics of the study population according to the quartiles of VFA}

The study subjects were also divided into four groups according to the quartiles of VFA in men and women. The analysis revealed a increasing trend in VFA that accompanied increases in BMI, WC, WHR, FM, FFM, PBF and TG in both genders, decreases in $25(\mathrm{OH}) \mathrm{D}_{3}$ in men and pre-menopausal women (Table 2, Table 3). Intergroup comparisons revealed that the Q2, Q3 and Q4 groups had significantly lower $25(\mathrm{OH}) \mathrm{D}_{3}$ than the Q1 group in men (Table 2), whereas the Q4 groups had significantly lower $25(\mathrm{OH}) \mathrm{D}_{3}$ than the $\mathrm{Q} 2$ group and Q1 group in premenopausal women (Table 3).

\section{Prevalence of vitamin D insufficiency and vitamin D deficiency according to the quartiles of VFA}

Figure 1a showed that the prevalence of vitamin D deficiency increased in men and in pre-menopausal women according to the quartiles of VFA $(P<0.05)$, but not in post-menopausal women $(P>0.05)$. The prevalence of vitamin $\mathrm{D}$ deficiency in the fourth quartile of VFA in men $(46.88 \%)$ and in pre-menopausal women $(28.10 \%)$ were significantly higher than that in the first quartile (15.63\% in men and $13.07 \%$ in pre-menopausal women), second quartile (35.38 \% in men and $16.67 \%$ in pre-menopausal women) and third quartile (35.94\% in men and $17.18 \%$ in pre-menopausal women $)(P<0.05)$ (Fig. 1a). Increased VFA was observed to be associated with higher vitamin $\mathrm{D}$ deficiency risk with a positive dose-response trend in men and pre-menopausal women ( $P$ for trend $<0.001)$, not in post-menopausal women. The prevalence of vitamin $\mathrm{D}$ insufficiency in the fourth quartile of VFA in men $(28.13 \%)$ was significantly higher than that in the first quartile $(9.23 \%)$ and second quartile (12.50\%) (Fig. 1b). However, the prevalence of vitamin $\mathrm{D}$ insufficiency did not increase with the 
Table 1 Descriptive characteristics of the study population

\begin{tabular}{|c|c|c|c|c|}
\hline Characteristics & Total & Men & Women & $P$-value ${ }^{a}$ \\
\hline$n$ & 1105 & 257 & 848 & \\
\hline Age, y & $43.82 \pm 12.15$ & $45.44 \pm 12.18$ & $43.33 \pm 12.11$ & 0.015 \\
\hline Body mass index, $\mathrm{kg} / \mathrm{m}^{2}$ & $23.67 \pm 3.37$ & $26.18 \pm 3.39$ & $22.90 \pm 2.97$ & $<0.001$ \\
\hline Waist circumference, $\mathrm{cm}$ & $82.79 \pm 9.08$ & $90.42 \pm 8.57$ & $80.48 \pm 7.90$ & $<0.001$ \\
\hline Waist-to- hip ratio & $0.87 \pm 0.05$ & $0.91 \pm 0.04$ & $0.84 \pm 0.04$ & $<0.001$ \\
\hline Fat mass, kg & $20.13 \pm 6.06$ & $21.45 \pm 6.91$ & $19.73 \pm 5.72$ & $<0.001$ \\
\hline Free fat mass, kg & $44.66 \pm 8.96$ & $58.41 \pm 6.56$ & $40.50 \pm 4.11$ & $<0.001$ \\
\hline Percentage body fat, $\%$ & $30.89 \pm 6.06$ & $26.35 \pm 5.57$ & $32.27 \pm 5.51$ & $<0.001$ \\
\hline Visceral fat area, $\mathrm{cm}^{2}$ & $87.30 \pm 35.44$ & $116.13 \pm 34.87$ & $78.56 \pm 30.68$ & $<0.001$ \\
\hline Systolic blood pressure, $\mathrm{mmHg}$ & $113.79 \pm 15.72$ & $120.54 \pm 12.72$ & $111.07 \pm 16.01$ & $<0.001$ \\
\hline Diastolic blood pressure, $\mathrm{mmHg}$ & $75.52 \pm 10.06$ & $80.30 \pm 9.34$ & $73.59 \pm 9.70$ & $<0.001$ \\
\hline Total cholesterol, mmol/L & $4.98 \pm 0.98$ & $5.03 \pm 0.95$ & $4.97 \pm 1.00$ & ${ }^{\mathrm{b}} \mathrm{NS}$ \\
\hline Triglycerides, mmol/L & $1.03(0.73-1.51)$ & $1.41(0.99-2.00)$ & $0.95(0.69-1.36)$ & $<0.001$ \\
\hline High-density lipoprotein cholesterol, mmol/L & $1.33 \pm 0.28$ & $1.16 \pm 0.21$ & $1.38 \pm 0.28$ & $<0.001$ \\
\hline Low-density lipoprotein cholesterol, mmol/L & $2.96 \pm 0.80$ & $3.10 \pm 0.76$ & $2.92 \pm 0.82$ & 0.001 \\
\hline Fasting plasma glucose, $\mathrm{mmol} / \mathrm{L}$ & $5.73 \pm 1.03$ & $5.96 \pm 1.28$ & $5.66 \pm 0.92$ & $<0.001$ \\
\hline $25(\mathrm{OH}) \mathrm{D}_{3}, \mu \mathrm{g} / \mathrm{L}$ & $36.46 \pm 24.70$ & $33.26 \pm 19.80$ & $37.44 \pm 25.94$ & 0.018 \\
\hline Smoking, \% yes & 11.86 & 42.80 & 2.48 & $<0.001$ \\
\hline Drinking, \% yes & 38.82 & 70.04 & 29.36 & $<0.001$ \\
\hline Doing exercise, $\%$ yes & 46.06 & 64.98 & 40.33 & $<0.001$ \\
\hline Sunshine time, h/day & $0.5(0.0,1.0)$ & $1.0(0.0,2.0)$ & $0.5(0.0,1.0)$ & $<0.001$ \\
\hline Vitamin D supplement users, \% yes & 2.26 & 2.33 & 2.24 & ${ }^{\mathrm{b}} \mathrm{NS}$ \\
\hline Obesity, \% & 13.76 & 29.18 & 9.08 & $<0.001$ \\
\hline \multicolumn{5}{|l|}{ Visceral fat obesity, \% } \\
\hline Men: WC $\geq 90 \mathrm{~cm}$; women: $W C \geq 80 \mathrm{~cm}$ & 44.71 & 50.58 & 42.92 & 0.031 \\
\hline Men: VFA $\geq 130 \mathrm{~cm}^{2} ;$ women: VFA $\geq 100 \mathrm{~cm}^{2}$ & 23.53 & 35.40 & 19.92 & $<0.001$ \\
\hline \multicolumn{5}{|l|}{$25(\mathrm{OH}) \mathrm{D}_{3}$ status $^{*}$} \\
\hline Vitamin D insufficiency, \% & 26.60 & 18.68 & 29.00 & 0.001 \\
\hline Vitamin D deficiency, \% & 24.89 & 33.46 & 22.29 & $<0.001$ \\
\hline
\end{tabular}

Values are percentages for categorical variables, means \pm SDs for continuous variables with a normal distribution, or medians (95 \% ranges) for continuous variables with a skewed distribution

Abbreviations: WC, waist circumference; VFA, visceral fat area; $25(\mathrm{OH}) \mathrm{D}_{3}, 25$-hydroxyvitamin $\mathrm{D}$

${ }^{a}$ Comparison among men and women

${ }^{\mathrm{b}} \mathrm{NS}=$ no significant at $p$ value $>.05$

* $25(\mathrm{OH}) \mathrm{D}_{3}$ status was defined as follows: A serum level of $25(\mathrm{OH}) \mathrm{D}_{3}<20 \mu \mathrm{g} / \mathrm{L}$ is considered to be vitamin $\mathrm{D}$ deficiency, whereas a level $20-29 \mu \mathrm{g} / \mathrm{L}$ is insufficient

quartiles of VFA in pre-menopausal women and postmenopausal women $(P>0.05)$ (Fig. 1b).

\section{Relationship between VFA and vitamin D insufficiency and deficiency}

Partial correlation analysis showed that serum $25(\mathrm{OH}) \mathrm{D}_{3}$ levels were negatively correlated with VFA and other body fatness indices in men (Fig. 2a-e) and pre-menopausal women (Fig. 2f-j) (all $P<0.05)$, not in post-menopausal women (Fig. 2k-o). We also assessed the odds ratios (ORs) and $95 \%$ confidence intervals (CIs) of VFA levels and vitamin D insufficiency and deficiency. After adjusting for age, smoking status, drinking status, exercise status, sun exposure and lipid profiles, as compared to individuals with the lowest VFA, those who had the highest VFA were at 4.9-fold risk of vitamin D insufficiency and deficiency (95 \% CI: 1.79213.365) in men and 1.8-fold risk of vitamin D insufficiency and deficiency (95\% CI: 1.051-3.210) in pre-menopausal women, not in post-menopausal women (Table 4).

\section{Discussion}

In this cross-sectional study, we confirmed that visceral fat obesity was an important risk factor of vitamin D 
Table 2 Characteristics of the study population according to quartiles of visceral fat area levels in men

\begin{tabular}{|c|c|c|c|c|c|}
\hline & \multicolumn{4}{|c|}{ Quartiles of visceral fat area $\left(\mathrm{cm}^{2}\right)$} & \multirow[t]{2}{*}{$P$-value } \\
\hline & Q1 (<89.95) & Q2 (89.95-115.72) & Q3 (115.72-140.46) & Q4 ( $\geq 140.46)$ & \\
\hline$n$ & 64 & 65 & 64 & 64 & \\
\hline Age, y & $42.36 \pm 12.69$ & $45.29 \pm 12.03$ & $46.92 \pm 12.06$ & $47.17 \pm 11.58$ & ${ }^{\mathrm{b}} \mathrm{NS}$ \\
\hline Body mass index, $\mathrm{kg} / \mathrm{m}^{2}$ & $22.87 \pm 2.23$ & $25.59 \pm 2.21^{\#}$ & $26.80 \pm 2.51^{\# \&}$ & $29.45 \pm 2.77^{\# \& \$}$ & 0.000 \\
\hline Waist circumference, $\mathrm{cm}$ & $81.28 \pm 5.58$ & $88.36 \pm 4.93^{\#}$ & $92.48 \pm 5.50^{\# \&}$ & $99.57 \pm 5.83^{\# \& \$}$ & 0.000 \\
\hline Waist-to-hip ratio & $0.86 \pm 0.03$ & $0.90 \pm 0.02^{\#}$ & $0.92 \pm 0.02^{\# \&}$ & $0.95 \pm 0.02^{\# \& \$}$ & 0.000 \\
\hline Fat mass, $\mathrm{kg}$ & $14.08 \pm 3.52$ & $19.90 \pm 3.67^{\#}$ & $23.35 \pm 4.97^{\# \&}$ & $28.51 \pm 5.64^{\# \& \$}$ & 0.000 \\
\hline Free fat mass, kg & $55.38 \pm 6.43$ & $57.40 \pm 6.06^{\#}$ & $58.17 \pm 5.60^{\# \&}$ & $62.75 \pm 5.93^{\# \& \$}$ & 0.000 \\
\hline Percentage body fat, \% & $20.14 \pm 3.63$ & $25.68 \pm 3.39^{\#}$ & $28.50 \pm 4.28^{\# \&}$ & $31.08 \pm 4.02^{\# \& \$}$ & 0.000 \\
\hline Systolic blood pressure, $\mathrm{mmHg}$ & $118.89 \pm 11.35$ & $121.78 \pm 12.12$ & $118.41 \pm 11.35$ & $122.93 \pm 14.70$ & ${ }^{\mathrm{b}} \mathrm{NS}$ \\
\hline Diastolic blood pressure, $\mathrm{mmHg}$ & $78.19 \pm 7.57$ & $80.22 \pm 10.05$ & $80.57 \pm 8.16$ & $81.95 \pm 10.95$ & ${ }^{\mathrm{b}} \mathrm{NS}$ \\
\hline Total cholesterol, $\mathrm{mmol} / \mathrm{L}$ & $4.71 \pm 0.78$ & $4.93 \pm 1.08$ & $5.17 \pm 0.90^{\#}$ & $5.31 \pm 0.90^{\# \&}$ & 0.001 \\
\hline Triglycerides, $\mathrm{mmol} / \mathrm{L}$ & $0.99(0.72-1.46)$ & $1.38(0.94-2.10)^{\#}$ & $1.53(1.22-2.11)^{\#}$ & $1.69(1.26-2.18)^{\#}$ & 0.036 \\
\hline High-density lipoprotein cholesterol, mmol/L & $1.22 \pm 0.23$ & $1.14 \pm 0.21$ & $1.13 \pm 0.21$ & $1.15 \pm 0.18$ & ${ }^{\mathrm{b}} \mathrm{NS}$ \\
\hline Low-density lipoprotein cholesterol, mmol/L & $2.85 \pm 0.66$ & $2.91 \pm 0.68$ & $3.24 \pm 0.76^{\# \&}$ & $3.44 \pm 0.79^{\# \&}$ & 0.000 \\
\hline Fasting plasma glucose, $\mathrm{mmol} / \mathrm{L}$ & $5.63 \pm 0.95$ & $6.10 \pm 1.36$ & $5.99 \pm 1.13$ & $6.13 \pm 1.58$ & ${ }^{\mathrm{b}} \mathrm{NS}$ \\
\hline $25(\mathrm{OH}) \mathrm{D}_{3}, \mu \mathrm{g} / \mathrm{L}$ & $42.30 \pm 19.59$ & $34.90 \pm 20.93^{\#}$ & $30.80 \pm 20.15^{\#}$ & $25.01 \pm 14.05^{\# \&}$ & 0.000 \\
\hline Smoking, \% yes & 28.13 & $41.54^{\#}$ & $43.75^{\#}$ & $57.81^{\#}$ & 0.009 \\
\hline Drinking, $\%$ yes & 57.81 & 73.85 & 71.88 & 76.56 & ${ }^{\mathrm{b}} \mathrm{NS}$ \\
\hline Doing exercise, $\%$ yes & 51.56 & 67.69 & 67.19 & 73.44 & ${ }^{\mathrm{b}} \mathrm{NS}$ \\
\hline Sunshine time, h/day & $1.00(0.50-1.00)$ & $1.00(0.00-3.00)$ & $0.50(0.00-1.50)$ & $1.00(0.00-2.00)$ & ${ }^{\mathrm{b}} \mathrm{NS}$ \\
\hline Vitamin D supplement users, \% yes & 1.56 & 0.00 & 6.25 & 1.56 & ${ }^{\mathrm{b}} \mathrm{NS}$ \\
\hline
\end{tabular}

Values are percentages for categorical variables, means \pm SDs for continuous variables with a normal distribution, or medians (95 \% ranges) for continuous variables with a skewed distribution

Abbreviations: $25(\mathrm{OH}) \mathrm{D}_{3}, 25$-hydroxyvitamin $\mathrm{D}_{3}$

${ }^{a}$ Comparison among four groups

${ }^{\mathrm{b}} \mathrm{NS}=$ no significant at $p$ value $>.05$

"Compared with Q1, $P<0.05$

${ }^{\&}$ Compared with Q2, $P<0.05$

\$Compared with Q3, $P<0.05$

insufficiency and deficiency among Chinese men and premenopausal women, and discovered the increase of visceral adiposity was positively associated with vitamin $\mathrm{D}$ insufficiency or deficiency risk with clear dose-response relationship.

There is evidence that vitamin D metabolism, storage, and action both influence and are influenced by adiposity. Observational studies have reported that an increased risk of vitamin D deficiency in those people with obesity [24]. Active vitamin D (1, 25-dihydroxyvitamin D) may influence the mobilisation of free fatty acids from the adipose tissue [25]. In vitro experiments in rats have also shown that large doses of vitamin $D_{2}$ lead to increases in energy expenditure due to uncoupling of oxidative phosphorylation in adipose tissues [26]. Consistent with the experimental studies, our result has indicated that serum $25(\mathrm{OH}) \mathrm{D}_{3}$ levels decreased significantly in subjects with visceral obesity and has shown that this decrease was closely correlated with fat distribution [27, 28].
Although the mechanism for the association between obesity and vitamin D insufficiency is not well understood, researches suggested that individuals with obesity were prone to vitamin D insufficiency [29-31], possibly as the result of increased sequestration of vitamin $D$ in the increased amounts of visceral adipose tissue in individuals with obesity [30]. This may lead to less vitamin D released into the blood, and consequently these individuals may have lower serum $25(\mathrm{OH}) \mathrm{D}_{3}$ levels. Such individuals may therefore need to increase their vitamin $\mathrm{D}$ intake to attain serum $25(\mathrm{OH}) \mathrm{D}_{3}$ levels comparable with individuals with normal BMI [29]. Evidence also suggests that vitamin D insufficiency may stimulate lipogenesis as the result of increased calcium influx into the adipocytes mediated by increased synthesis of parathyroid hormones [32]. This would suggest that vitamin D insufficiency could cause obesity. Minimal outdoor activity and maximum skin covering by clothing among the population with obesity also limits photochemical subcutaneous synthesis of vitamin D 
Table 3 Characteristics of the study population according to quartiles of visceral fat area levels in women

\begin{tabular}{|c|c|c|c|c|c|}
\hline & Pre-menopausal & men & & & \\
\hline$n$ & $\begin{array}{l}\text { Quartiles of visc } \\
\text { Q1 }(<53.15) \\
153\end{array}$ & $\begin{array}{l}\text { fat area }\left(\mathrm{cm}^{2}\right) \\
\text { Q2 }(53.15-66.18) \\
144\end{array}$ & $\begin{array}{l}\text { Q3 (66.18-84.47) } \\
163\end{array}$ & $\begin{array}{l}\text { Q4 ( }(\geq 84.47) \\
153\end{array}$ & $P$-value ${ }^{a}$ \\
\hline Age, y & $33.09 \pm 6.30$ & $36.54 \pm 7.54^{\#}$ & $38.35 \pm 6.91^{\# \&}$ & $41.27 \pm 7.41^{\# \& \$}$ & 0.000 \\
\hline Body mass index, $\mathrm{kg} / \mathrm{m}^{2}$ & $20.51 \pm 1.33$ & $21.54 \pm 1.46^{\#}$ & $22.44 \pm 1.77^{\# \&}$ & $25.48 \pm 3.46^{\# \& \$}$ & 0.000 \\
\hline Waist circumference, $\mathrm{cm}$ & $73.06 \pm 3.74$ & $76.67 \pm 3.48^{\#}$ & $79.62 \pm 3.92^{\# \&}$ & $88.27 \pm 7.90^{\# \& \$}$ & 0.000 \\
\hline Waist-to-hip ratio & $0.81 \pm 0.02$ & $0.84 \pm 0.02^{\#}$ & $0.86 \pm 0.02^{\# \&}$ & $0.90 \pm 0.04^{\# \& \$}$ & 0.000 \\
\hline Fat mass, kg & $14.39 \pm 2.71$ & $17.02 \pm 2.90^{\#}$ & $18.99 \pm 3.08^{\# \&}$ & $24.93 \pm 5.80^{\# \& \$}$ & 0.000 \\
\hline Free fat mass, kg & $39.65 \pm 3.46$ & $39.84 \pm 3.69$ & $40.16 \pm 3.42$ & $43.23 \pm 4.85^{\# \& \$}$ & 0.000 \\
\hline Percentage body fat, $\%$ & $26.53 \pm 3.69$ & $29.85 \pm 3.74^{\#}$ & $32.01 \pm 3.58^{\# \&}$ & $36.26 \pm 4.46^{\# \& \$}$ & 0.000 \\
\hline Systolic blood pressure, $\mathrm{mmHg}$ & $102.64 \pm 12.01$ & $102.31 \pm 10.81$ & $106.97 \pm 112.46^{\#}$ & $110.85 \pm 15.45^{\# \&}$ & 0.000 \\
\hline Diastolic blood pressure, mmHg & $69.03 \pm 8.46$ & $69.18 \pm 7.37$ & $72.13 \pm 8.73$ & $74.38 \pm 10.18^{\# \&}$ & 0.001 \\
\hline Total cholesterol, mmol/L & $4.42 \pm 0.72$ & $4.63 \pm 0.77^{\#}$ & $4.73 \pm 0.87^{\#}$ & $4.90 \pm 0.87^{\# \& \$}$ & 0.000 \\
\hline Triglycerides, $\mathrm{mmol} / \mathrm{L}$ & $0.66(0.58-0.86)$ & $0.79(0.64-1.07)^{\#}$ & $0.94(0.69-1.25)^{\# \&}$ & $1.16(0.80-1.55)^{\# \& \$}$ & 0.000 \\
\hline High-density lipoprotein cholesterol, mmol/L & $1.46 \pm 0.29$ & $1.41 \pm 0.30$ & $1.32 \pm 0.24^{\# \&}$ & $1.26 \pm 0.25^{\# \&}$ & 0.000 \\
\hline Low-density lipoprotein cholesterol, mmol/L & $2.41 \pm 0.62$ & $2.64 \pm 0.63^{\#}$ & $2.81 \pm 0.76^{\# \&}$ & $3.02 \pm 0.75^{\# \& \$}$ & 0.000 \\
\hline Fasting plasma glucose, $\mathrm{mmol} / \mathrm{L}$ & $5.29 \pm 0.47$ & $5.37 \pm 0.45$ & $5.55 \pm 0.78^{\# \&}$ & $5.77 \pm 0.90^{\# \& \$}$ & 0.000 \\
\hline $25(\mathrm{OH}) \mathrm{D}_{3}, \mu \mathrm{g} / \mathrm{L}$ & $43.25 \pm 28.90$ & $42.30 \pm 28.02$ & $38.39 \pm 24.11$ & $35.80 \pm 27.38^{\# \&}$ & 0.002 \\
\hline Smoking, $\%$ yes & 0.65 & 0.69 & 0.61 & 0.65 & ${ }^{b} \mathrm{NS}$ \\
\hline Drinking, \% yes & 22.22 & 25.00 & 24.54 & 29.41 & ${ }^{b} N S$ \\
\hline Doing exercise, $\%$ yes & 44.44 & 48.61 & 43.56 & 47.06 & ${ }^{\mathrm{b}} \mathrm{NS}$ \\
\hline Sunshine time, $\mathrm{h} / \mathrm{day}$ & $1.00(0.50-0.10)$ & $1.00(0.00-1.00)$ & $1.00(0.50-0.10)$ & $1.00(0.50-0.10)$ & ${ }^{b} \mathrm{NS}$ \\
\hline Vitamin D supplement users, $\%$ yes & 1.96 & 0.69 & 1.23 & 0.65 & ${ }^{\mathrm{b}} \mathrm{NS}$ \\
\hline & Post-menopausa & omen & & & \\
\hline & Quartiles of visc & fat area $\left(\mathrm{cm}^{2}\right)$ & & & $P$-value \\
\hline & Q1 $(<71.55)$ & Q2(71.55-91.97) & Q3(91.97-115.73) & $\mathrm{Q} 4(\geq 115.73)$ & \\
\hline$n$ & 59 & 59 & 59 & 58 & \\
\hline Age, y & $58.17 \pm 7.74$ & $59.25 \pm 5.49$ & $58.95 \pm 5.60$ & $59.38 \pm 5.81$ & ${ }^{b} \mathrm{NS}$ \\
\hline Body mass index, $\mathrm{kg} / \mathrm{m}^{2}$ & $21.43 \pm 1.60$ & $22.62 \pm 1.22^{\#}$ & $24.18 \pm 2.00^{\# \&}$ & $27.64 \pm 2.51^{\# \& \$}$ & 0.000 \\
\hline Waist circumference, $\mathrm{cm}$ & $75.57 \pm 4.19$ & $79.47 \pm 2.73^{\#}$ & $84.24 \pm 4.41^{\# \&}$ & $93.64 \pm 6.10^{\# \& \$}$ & 0.000 \\
\hline Waist-to-hip ratio & $0.82 \pm 0.02$ & $0.86 \pm 0.01^{\#}$ & $0.89 \pm 0.01^{\# \&}$ & $0.93 \pm 0.03^{\# \& \$}$ & 0.000 \\
\hline Fat mass, $\mathrm{kg}$ & $16.80 \pm 2.85$ & $19.42 \pm 2.35^{\#}$ & $22.66 \pm 3.51^{\# \&}$ & $29.18 \pm 4.87^{\# \& \$}$ & 0.000 \\
\hline Free fat mass, $\mathrm{kg}$ & $38.72 \pm 3.89$ & $38.79 \pm 2.88$ & $39.66 \pm 3.24$ & $42.51 \pm 4.45^{\# \& \$}$ & 0.000 \\
\hline Percentage body fat, \% & $30.18 \pm 3.77$ & $33.34 \pm 3.03^{\#}$ & $36.25 \pm 3.45^{\# \&}$ & $40.55 \pm 3.97^{\# \& \$}$ & 0.000 \\
\hline Systolic blood pressure, $\mathrm{mmHg}$ & $115.14 \pm 14.90$ & $120.78 \pm 18.67$ & $122.36 \pm 13.65$ & $124.88 \pm 15.37$ & ${ }^{b} \mathrm{NS}$ \\
\hline Diastolic blood pressure, $\mathrm{mmHg}$ & $75.97 \pm 9.47$ & $76.72 \pm 8.67$ & $77.22 \pm 8.23$ & $81.63 \pm 10.04^{\# \& \$}$ & 0.029 \\
\hline Total cholesterol, mmol/L & $5.64 \pm 0.93$ & $5.84 \pm 0.10$ & $5.88 \pm 1.17$ & $5.58 \pm 0.82$ & ${ }^{b} \mathrm{NS}$ \\
\hline Triglycerides, mmol/L & $1.10(0.67-1.40)$ & $1.21(0.93-1.50)^{\#}$ & $1.40(1.07-1.94)^{\# \&}$ & $158(1.16-1.89)^{\# \&}$ & 0.000 \\
\hline High-density lipoprotein cholesterol, mmol/L & $1.55 \pm 0.30$ & $1.42 \pm 0.23^{\#}$ & $1.33 \pm 0.25^{\#}$ & $1.35 \pm 0.26^{\#}$ & 0.000 \\
\hline Low-density lipoprotein cholesterol, mmol/L & $3.31 \pm 0.80$ & $3.57 \pm 0.73$ & $3.54 \pm 0.85$ & $3.33 \pm 0.81$ & ${ }^{b} \mathrm{NS}$ \\
\hline Fasting plasma glucose, $\mathrm{mmol} / \mathrm{L}$ & $5.75 \pm 1.34$ & $6.06 \pm 1.13$ & $6.35 \pm 1.51$ & $6.10 \pm 0.84$ & ${ }^{b} \mathrm{NS}$ \\
\hline $25(\mathrm{OH}) \mathrm{D}_{3}, \mu \mathrm{g} / \mathrm{L}$ & $33.04 \pm 22.62$ & $33.63 \pm 20.89$ & $29.77 \pm 20.90$ & $27.78 \pm 19.64$ & ${ }^{\mathrm{b}} \mathrm{NS}$ \\
\hline Smoking, \% yes & 3.39 & 6.78 & 8.47 & 10.34 & ${ }^{b}$ NS \\
\hline Drinking, $\%$ yes & 33.90 & 38.98 & 40.68 & 46.55 & ${ }^{b} N S$ \\
\hline
\end{tabular}


Table 3 Characteristics of the study population according to quartiles of visceral fat area levels in women (Continued)

\begin{tabular}{|c|c|c|c|c|c|}
\hline Doing exercise, $\%$ yes & 32.20 & 30.51 & 22.03 & 18.97 & ${ }^{\mathrm{b}} \mathrm{NS}$ \\
\hline Sunshine time, h/day & $1.00(0.50-0.10)$ & $1.00(0.00-1.00)$ & $1.00(0.50-0.10)$ & $1.00(0.50-0.10)$ & ${ }^{b} \mathrm{NS}$ \\
\hline Vitamin D supplement users, \% yes & 3.39 & 5.08 & 6.78 & 5.17 & ${ }^{b} N S$ \\
\hline
\end{tabular}

Values are percentages for categorical variables, means \pm SDs for continuous variables with a normal distribution, or medians (95 \% ranges) for continuous variables with a skewed distribution

Abbreviations: $25(\mathrm{OH}) \mathrm{D}_{3}, 25$-hydroxyvitamin $\mathrm{D}_{3}$

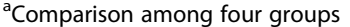

${ }^{\mathrm{b}} \mathrm{NS}=$ no significant at $p$ value $>.05$

"Compared with Q1, $P<0.05$

${ }^{8}$ Compared with Q2, $P<0.05$

${ }^{\$}$ Compared with Q3, $P<0.05$

[31]. Although we have found an association between VFA and vitamin D insufficiency and deficiency, we used crosssectional data, and thus, were precluded from establishing a temporal relationship between VFA and vitamin D

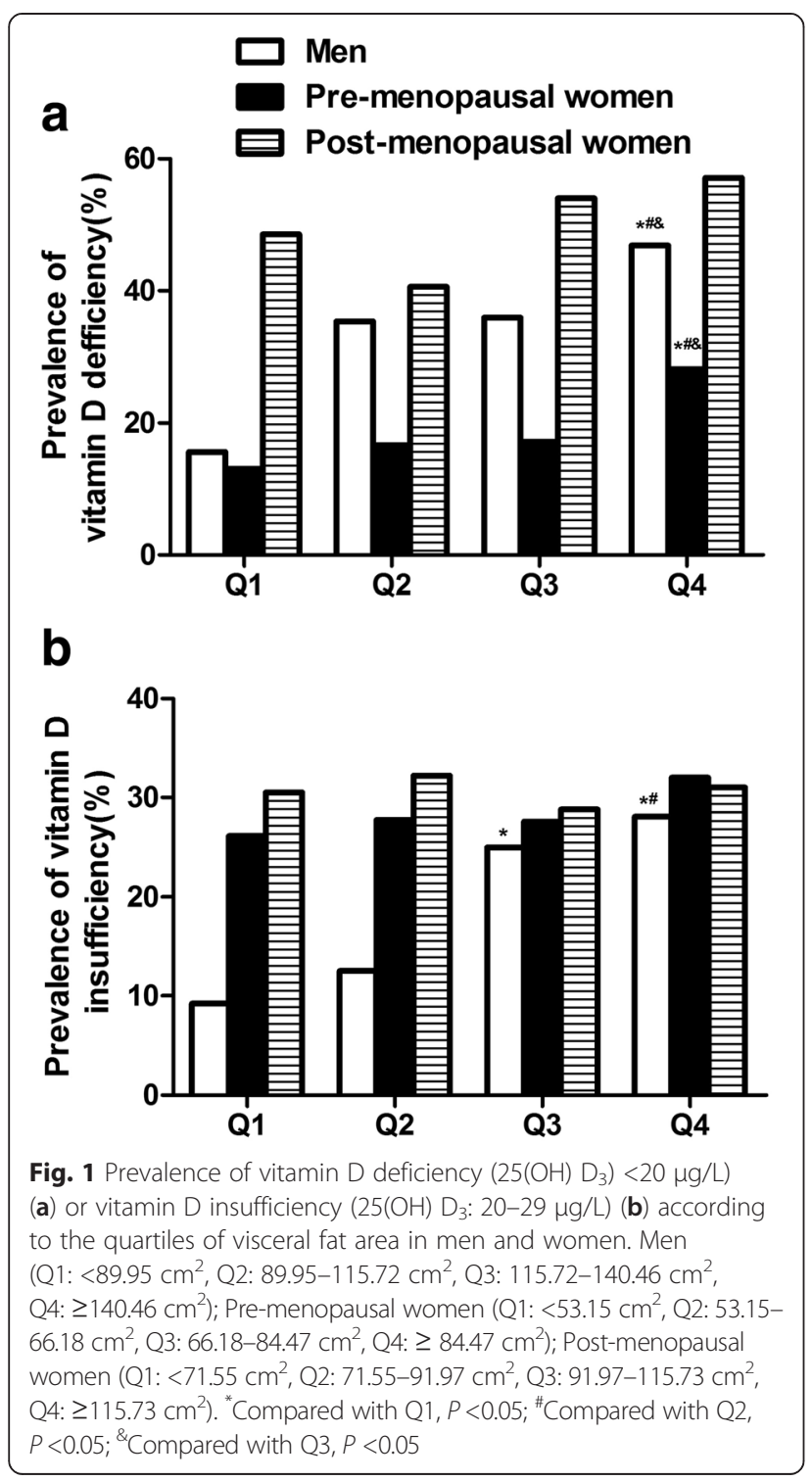

insufficiency and deficiency. However, clinical trials have failed to conclusively demonstrate the benefits of vitamin D supplementation. Randomized controlled trials testing the effect of vitamin D supplementation on weight loss in individuals with obesity or overweight have provided inconsistent findings [33-35]. Dilution related to the greater volume of distribution has been recently proposed as the most likely explanation for the lower $25(\mathrm{OH}) \mathrm{D}_{3}$ concentrations in individuals with obesity [36]. In that study, no evidence was found for reduced bioavailability through increased sequestration of vitamin D in the adipose tissue, which had previously been suggested to contribute to the low $25(\mathrm{OH}) \mathrm{D}_{3}$ concentrations in obesity. Therefore, these results suggested that although increased in vitamin $\mathrm{D}$ status were not likely to help with weight regulation, increased risk of vitamin D deficiency could contribute to the adverse health effects associated with obesity. Recent study has showed that higher BMI led to lower vitamin D status, providing evidence for the role of obesity as a causal risk factor for the development of vitamin D deficiency on the basis of a bi-directional genetic approach [37].

Next to common adiposity measures, we also discovered that VFA was inversely associated with serum $25(\mathrm{OH}) \mathrm{D}_{3}$ concentrations in Chinese men and pre-menopausal women, which was similar to the recent study in Northeast Germany and Denmark [38] and China [16]. Differed from Hao's study among Chinese population, our study population included men and women, and included the participants who were diabetes. Especially, we have observed that the men had the higher risk for vitamin D insufficiency and deficiency. It was because the prevalence of obesity and visceral obesity in men was higher than in women. Obesity is known to be associated with decreased bioavailability of vitamin $\mathrm{D}$, which is sequestered in body fat [30]. Moreover, there was a clear difference in the relationship of VFA and vitamin $\mathrm{D}$ insufficiency and deficiency between post- and pre-menopausal women in our study. On one hand, the prevalence of vitamin D insufficiency and deficiency in our study was higher in post-menopausal women. The vitamin $\mathrm{D}$ inadequacy is also present in many postmenopausal women in European, North American countries and 


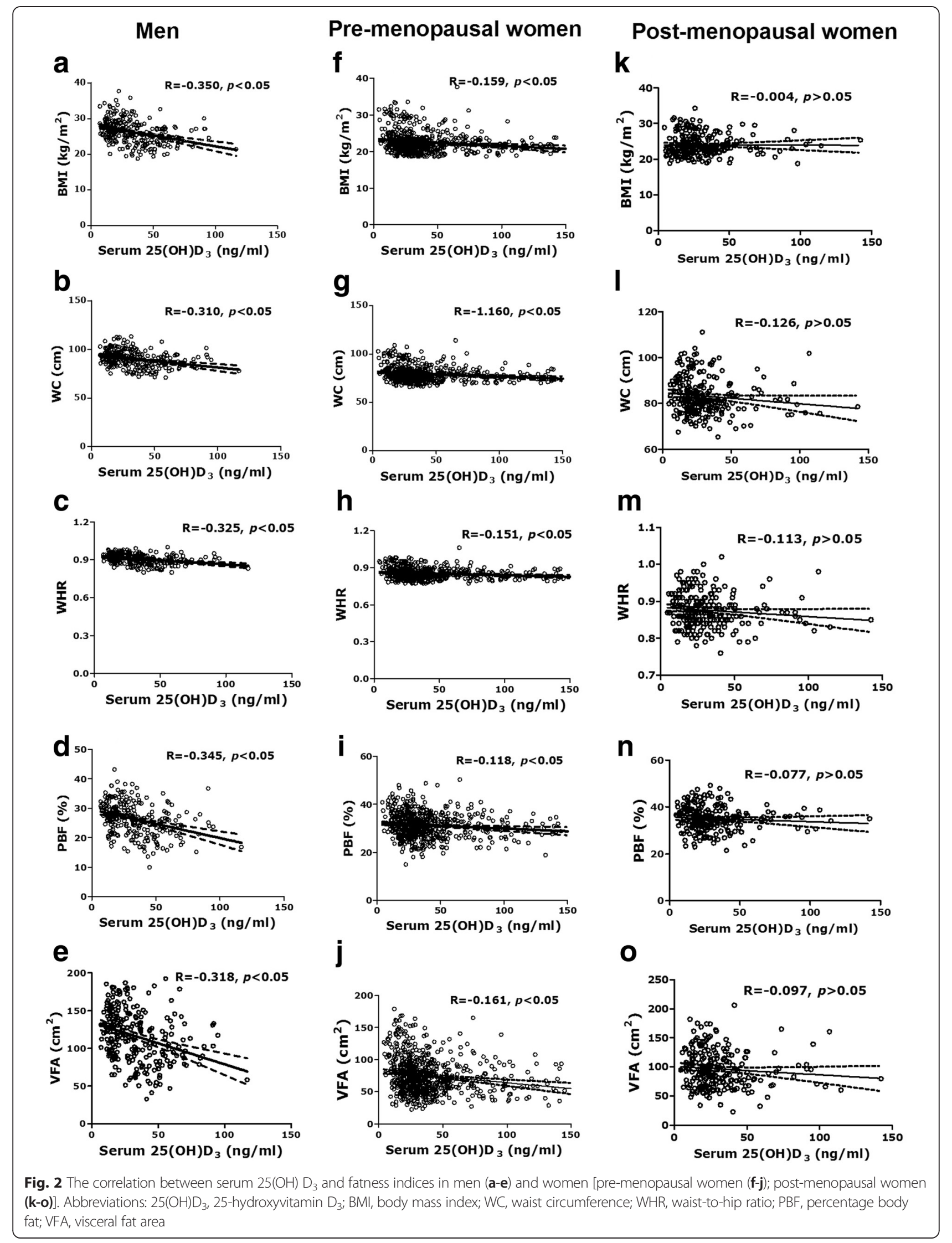


Table 4 The odd ratios of different fatness indices and vitamin D insufficiency and deficiency in men and women

\begin{tabular}{|c|c|c|c|c|c|}
\hline \multirow[t]{2}{*}{ Gender } & \multirow[t]{2}{*}{ Fatness indices } & \multicolumn{2}{|l|}{ Crude model } & \multicolumn{2}{|l|}{ Adjusted model $^{a}$} \\
\hline & & OR $(95 \% \mathrm{Cl})$ & $P$-Value & OR $(95 \% \mathrm{Cl})$ & $P$-Value \\
\hline \multirow[t]{16}{*}{ Men } & Visceral fat area & & & & \\
\hline & $\mathrm{Q} 1\left(<89.95 \mathrm{~cm}^{2}\right)$ & 1.0 & & 1.0 & \\
\hline & Q2(89.95-115.72 $\left.\mathrm{cm}^{2}\right)$ & $2.059(0.990-4.281)$ & 0.053 & $1.320(0.476-3.662)$ & 0.594 \\
\hline & Q3(115.72-140.46 $\left.\mathrm{cm}^{2}\right)$ & $3.987(1.900-8.364)$ & 0.000 & $2.424(0.916-6.417)$ & 0.075 \\
\hline & $\mathrm{Q} 4\left(\geq 140.46 \mathrm{~cm}^{2}\right)$ & $7.667(3.495-16.817)$ & 0.000 & $4.894(1.792-13.365)$ & 0.002 \\
\hline & Continuous & $1.025(1.016-1.034)$ & & $1.719(1.251-2.361)$ & \\
\hline & $P$-value for trend & 0.000 & & 0.001 & \\
\hline & Body mass index & & & & \\
\hline & $<28 \mathrm{~kg} / \mathrm{m}^{2}$ & 1.0 & & 1.0 & \\
\hline & $\geq 28 \mathrm{~kg} / \mathrm{m}^{2}$ & $3.930(2.162-7.142)$ & 0.000 & $2.857(1.360-6.001)$ & 0.006 \\
\hline & Waist circumference & & & & \\
\hline & $<90 \mathrm{~cm}$ & 1.0 & & 1.0 & \\
\hline & $\geq 90 \mathrm{~cm}$ & $3.007(1.809-4.998)$ & 0.000 & $2.199(1.130-4.279)$ & 0.020 \\
\hline & Waist-to-hip ratio & & & & \\
\hline & $<0.90$ & 1.0 & & 1.0 & \\
\hline & $\geq 0.90$ & $3.802(2.210-6.539)$ & 0.000 & 2.052(1.010-4.169) & 0.047 \\
\hline \multirow[t]{16}{*}{ Pre-menopausal women } & Visceral fat area & & & & \\
\hline & $\mathrm{Q} 1\left(<53.15 \mathrm{~cm}^{2}\right)$ & 1.0 & & 1.0 & \\
\hline & Q2(53.15-66.18 $\left.\mathrm{cm}^{2}\right)$ & $1.240(0.781-1.968)$ & 0.361 & $1.097(0.644-1.868)$ & 0.735 \\
\hline & Q3 $\left(66.18-84.47 \mathrm{~cm}^{2}\right)$ & $1.257(0.803-1.068)$ & 0.317 & 1.215(0.717-2.059) & 0.469 \\
\hline & $\mathrm{Q} 4\left(\geq 84.47 \mathrm{~cm}^{2}\right)$ & $2.338(1.478-3.697)$ & 0.000 & $1.837(1.051-3.210)$ & 0.033 \\
\hline & Continuous & $1.013(1.008-1.018)$ & & $1.265(1.037-1.543)$ & \\
\hline & $P$-value for trend & 0.000 & & 0.030 & \\
\hline & Body mass index & & & & \\
\hline & $<28 \mathrm{~kg} / \mathrm{m}^{2}$ & 1.0 & & 1.0 & \\
\hline & $\geq 28 \mathrm{~kg} / \mathrm{m}^{2}$ & $3.921(1.952-7.875)$ & 0.000 & $3.052(1.430-6.514)$ & 0.004 \\
\hline & Waist circumference & & & & \\
\hline & $<80 \mathrm{~cm}$ & 1.0 & & 1.0 & \\
\hline & $\geq 80 \mathrm{~cm}$ & $1.809(1.297-2.523)$ & 0.000 & $1.647(1.121-2.419)$ & 0.011 \\
\hline & Waist-to-hip ratio & & & & \\
\hline & $<0.85$ & 1.0 & & 1.0 & \\
\hline & $\geq 0.85$ & $1.487(1.081-2.046)$ & 0.015 & $1.281(0.878-1.871)$ & 0.199 \\
\hline \multirow[t]{11}{*}{ Post-menopausal women } & Visceral fat area & & & & \\
\hline & $\mathrm{Q} 1\left(<71.55 \mathrm{~cm}^{2}\right)$ & 1.0 & & 1.0 & \\
\hline & Q2 $\left(71.55-91.97 \mathrm{~cm}^{2}\right)$ & $0.813(0.392-1.686)$ & 0.577 & $0.912(0.359-2.319)$ & 0.847 \\
\hline & Q3(91.97-115.73 cm²) & $1.153(0.550-2.418)$ & 0.706 & $1.254(0.506-3.106)$ & 0.625 \\
\hline & $\mathrm{Q} 4\left(\geq 115.73 \mathrm{~cm}^{2}\right)$ & $1.800(0.829-3.909)$ & 0.137 & $2.326(0.903-5.991)$ & 0.080 \\
\hline & Continuous & $1.010(1.001-1.019)$ & & $1.012(1.002-1.022)$ & \\
\hline & $P$-value for trend & 0.028 & & 0.024 & \\
\hline & Body mass index & & & & \\
\hline & $<28 \mathrm{~kg} / \mathrm{m}^{2}$ & 1.0 & & 1.0 & \\
\hline & $\geq 28 \mathrm{~kg} / \mathrm{m}^{2}$ & 1.577(0.691-3.598) & 0.279 & $1.379(0.548-3.470)$ & 0.494 \\
\hline & Waist circumference & & & & \\
\hline
\end{tabular}


Table 4 The odd ratios of different fatness indices and vitamin D insufficiency and deficiency in men and women (Continued)

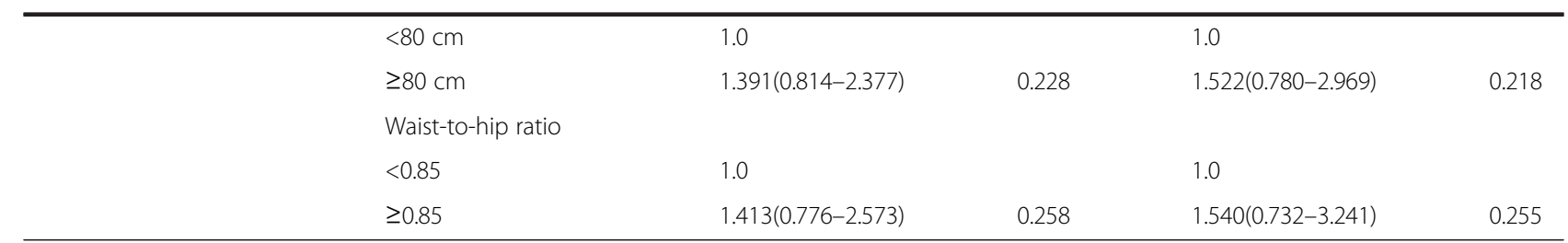

${ }^{a}$ Adjusted for age, smoking status, drinking status, exercise status, sunshine time and lipid profiles

Eastern Asia [39-42]. On the other hand, there was no difference in the vitamin D insufficiency and deficiency across the quartiles of VFA among post-menopausal women. Thus, we did not observe a relationship between VFA and vitamin D insufficiency and deficiency in post-menopausal women.

Still other studies have implicated the decreased level of serum $25(\mathrm{OH}) \mathrm{D}_{3}$ was considered as a risk factor for obesity and its related metabolic disorders including hypertension, high pulse pressure, obesity, hyperlipidemia, diabetes, etc., which increases the chance of cardiovascular disease [43-48]. Currently, researches on vitamin $\mathrm{D}$ and metabolic syndrome or its components, which are known to increase cardiovascular disease, are being conducted all over the world [49-52]. Compared with the non-metabolic syndrome group, serum $25(\mathrm{OH}) \mathrm{D}_{3}$ levels were significantly lower in the metabolic syndrome group [52]. Lu et al. [50] have reported that reduced serum $25(\mathrm{OH}) \mathrm{D}_{3}$ levels were associated with metabolic syndrome and its components, and in particular, obesity was highly associated with insulin resistance and serum $25(\mathrm{OH}) \mathrm{D}_{3}$ when compared to normal weight. Among Korean studies, metabolic syndrome and hypertension were associated with serum $25(\mathrm{OH}) \mathrm{D}_{3}$ levels in a study of middle-aged Koreans [51]. In fact, Forouhi et al. reported a significant interaction between 25(OH) D and BMI on the risk for a 10-year increase in HOMA-IR [52]. Moreover, the release of free fatty acids from adipose tissue can induce insulin resistance, whereas 1, 25-hydroxyvitamin $\mathrm{D}$ has been shown to counteract the free fatty acid-induced insulin resistance [53]. The stronger association of vitamin $D$ with insulin resistance among the participants with visceral fat obesity suggests that adequate vitamin D status is more important for the prevention of insulin resistance and metabolic syndrome in these individuals. In addition, a larger VFA was strongly related to a higher prevalence of impaired fasting glucose levels [54], diabetes [54], insulin resistance [54], hypertension [55], abnormality of lipid metabolism [56], and metabolic risk factors $[56,57]$. In our study, the prevalence of hyperglycemia and hypertriglyceridemia increased with the quartiles of VFA in both genders (Appendix Table 1), and VFA was closely related with the indices of metabolic disorders (Appendix Table 2). The individuals with the higher VFA levels have the higher risk of hyperglycemia and hypertriglyceridemia in both genders (Appendix Table 3). In accordance with our finding, one study has demonstrated that the VFA rather than the WC itself was a major determinant of metabolic syndrome in premenopausal Korean women [58], whereas the WC and VFA were similarly useful in identifying metabolic syndrome in elderly Korean women [59]. Our study highlights VFA might also be a simple and sensitive index in routine use for screening vitamin $\mathrm{D}$ deficiency and vitamin $\mathrm{D}$ related disease among general.

This study has several limitations. First, the crosssectional study design precluded the ability to determine a causal relationship between VFA and vitamin D insufficiency and deficiency. Second, the DEXA, $\mathrm{CT}$ and MRI were not used to measure visceral fat mass for our study because the participants in our study from the routine health check-up. The DEXA, CT and MRI were not the regular item of health check-up since they require expensive and specialized equipment, and exposure to radiation. Third, the intact parathyroid hormone (iPTH) is also expected to be a relevant confounder or even the causal factor of the association between VFA and $25(\mathrm{OH}) \mathrm{D}_{3}$, and our study often concentrated exclusively on $25(\mathrm{OH}) \mathrm{D}_{3}$ or $\mathrm{iPTH}$ without considering the interaction between both. In addition, menopausal status was based on self-reporting. Therefore, further cohort study will be conducted to observe the causal relations between VFA and vitamin D insufficiency and deficiency.

\section{Conclusion}

In conclusion, results of our study revealed that higher VFA increases the risk of vitamin D insufficiency and deficiency in men and pre-menopausal women, but not in post-menopausal women. VFA is a better and convenience surrogate marker for visceral adipose measurement and could be used in identifying the risk of vitamin D insufficiency and deficiency in routine health examination. 


\section{Appendix Table 1}

Table 5 Prevalence of components of metabolic syndrome according to quartiles of visceral fat area

\begin{tabular}{|c|c|c|c|c|c|}
\hline & \multicolumn{4}{|l|}{ Men } & \multirow{3}{*}{$P$-value } \\
\hline & \multicolumn{4}{|c|}{ Quartiles of visceral fat area $\left(\mathrm{cm}^{2}\right)$} & \\
\hline & $\overline{Q 1(<89.95)}$ & Q2(89.95-115.72) & Q3(115.72-140.46) & $\mathrm{Q} 4(\geq 140.46)$ & \\
\hline$n$ & 64 & 65 & 64 & 64 & \\
\hline Hyperglycemia & $5(7.81)$ & $20(30.77)^{\#}$ & $17(26.56)^{\#}$ & $19(29.69)^{\#}$ & 0.006 \\
\hline Hypertriglyceridemia & $12(18.75)$ & $21(32.31)$ & $28(43.75)^{\#}$ & $31(48.44)^{\#}$ & 0.002 \\
\hline Low HDL-C & $14(21.88)$ & 19(29.23) & 23(35.94) & 19(29.69) & ${ }^{\mathrm{b}} \mathrm{NS}$ \\
\hline \multirow[t]{4}{*}{ High blood pressure } & $12(18.75)$ & $16(24.62)$ & $16(25.00)$ & 19(29.68) & ${ }^{\mathrm{b}} \mathrm{NS}$ \\
\hline & \multicolumn{4}{|c|}{ Pre-menopausal women } & \\
\hline & \multicolumn{4}{|c|}{ Quartiles of visceral fat area $\left(\mathrm{cm}^{2}\right)$} & $P$-value ${ }^{a}$ \\
\hline & $\mathrm{Q} 1(<53.15)$ & Q2(53.15-66.18) & Q3(66.18-84.47) & $\mathrm{Q} 4(\geq 84.47)$ & \\
\hline$n$ & 153 & 144 & 163 & 153 & \\
\hline Hyperglycemia & $2(1.31)$ & $8(5.56)$ & $16(9.82)^{\#}$ & $38(24.84)^{\# \& \$}$ & 0.000 \\
\hline Hypertriglyceridemia & $2(1.31)$ & $8(5.56)$ & $19(11.66)^{\#}$ & $29(18.95)^{\# \&}$ & 0.000 \\
\hline Low HDL-C & $41(26.80)$ & $54(37.50)$ & $76(46.63)^{\#}$ & $93(60.78)^{\# \& \$}$ & 0.000 \\
\hline \multirow[t]{4}{*}{ High blood pressure } & $2(1.31)$ & $4(2.77)$ & $11(6.75)^{\#}$ & $21(13.73)^{\# \& \$}$ & 0.000 \\
\hline & \multicolumn{5}{|c|}{ Post-menopausal women } \\
\hline & \multicolumn{4}{|c|}{ Quartiles of visceral fat area $\left(\mathrm{cm}^{2}\right)$} & $P$-value ${ }^{a}$ \\
\hline & $\mathrm{Q} 1(<71.55)$ & Q2(71.55-91.97) & Q3(91.97-115.73) & $\mathrm{Q} 4(\geq 115.73)$ & \\
\hline$n$ & 59 & 59 & 59 & 58 & \\
\hline Hyperglycemia & $12(20.34)$ & $22(37.29)$ & $26(44.07)^{\#}$ & $22(37.93)^{\#}$ & 0.045 \\
\hline Hypertriglyceridemia & $7(11.86)$ & 10(16.95) & $20(33.90)^{\#}$ & $24(41.38)^{\# \&}$ & 0.001 \\
\hline Low HDL-C & 13(22.03) & 20(33.90) & $28(47.46)^{\#}$ & $26(44.83)^{\#}$ & 0.017 \\
\hline High blood pressure & $12(18.64)$ & $17(28.81)$ & $15(25.42)$ & 19(32.76) & ${ }^{\mathrm{b}} \mathrm{NS}$ \\
\hline
\end{tabular}

The metabolic risk factors were defined as follows: (1) high blood pressure, with systolic blood pressure of at least $130 \mathrm{mmHg}$ or diastolic blood pressure of at least $85 \mathrm{mmHg}$ or taking medication for previously diagnosed hypertension; (2) hypertriglyceridemia, with TG levels of at least $150 \mathrm{mg} / \mathrm{dL}$ (1.69 mmol/L); (3) low HDL-C, with HDL cholesterol level less than $40 \mathrm{mg} / \mathrm{dL}(1.03 \mathrm{mmol} / \mathrm{L})$ for men and less than $50 \mathrm{mg} / \mathrm{dL}$ (1.29 mmol/L) for women; (4) hyperglycemia, with fasting plasma glucose of at least $110 \mathrm{mg} / \mathrm{dL}(6.1 \mathrm{mmol} / \mathrm{L})$ or taking medication for previously diagnosed type 2 diabetes

Values are number (percentages)

${ }^{a}$ Comparison among four groups

${ }^{\mathrm{b}} \mathrm{NS}=$ no significant at $p$ value $>.05$

\#Compared with Q1, $P<0.05$

${ }^{\&}$ Compared with Q2, $P<0.05$

\$Compared with Q3, $P<0.05$ 


\section{Appendix Table 2}

Table 6 Correlation coefficients of the relationships between visceral fat area and various parameters of metabolic risk factors

\begin{tabular}{|c|c|c|c|c|c|c|}
\hline \multirow[t]{2}{*}{ Indices } & \multicolumn{2}{|l|}{ Men } & \multicolumn{2}{|c|}{ Pre-menopausal women } & \multicolumn{2}{|c|}{ Post-menopausal women } \\
\hline & r & $P$-value & r & $P$-value & $r$ & $P$-value \\
\hline Body mass index & 0.763 & 0.000 & 0.719 & 0.000 & 0.818 & 0.000 \\
\hline Waist circumference & 0.818 & 0.000 & 0.949 & 0.000 & 0.879 & 0.000 \\
\hline Waist-to- hip ratio & 0.899 & 0.000 & 0.893 & 0.000 & 0.930 & 0.000 \\
\hline Systolic blood pressure & 0.112 & 0.152 & 0.283 & 0.000 & 0.221 & 0.007 \\
\hline Diastolic blood pressure & 0.162 & 0.038 & 0.296 & 0.000 & 0.236 & 0.004 \\
\hline Total cholesterol & 0.211 & 0.007 & 0.218 & 0.000 & -0.013 & 0.842 \\
\hline Triglycerides & 0.140 & 0.025 & 0.382 & 0.000 & 0.262 & 0.000 \\
\hline High-density lipoprotein cholesterol & -0.198 & 0.011 & -0.240 & 0.000 & -0.254 & 0.000 \\
\hline Low-density lipoprotein cholesterol & 0.326 & 0.000 & 0.297 & 0.000 & 0.004 & 0.957 \\
\hline Fasting plasma glucose & 0.128 & 0.040 & 0.259 & 0.000 & 0.105 & 0.107 \\
\hline
\end{tabular}

\section{Appendix Table 3}

Table 7 Multivariate analysis of the ORs and $95 \%$ Cls between visceral fat area and components of metabolic syndrome

\begin{tabular}{|c|c|c|c|c|}
\hline & \multicolumn{4}{|c|}{ Quartiles of visceral fat area } \\
\hline & $\overline{\mathrm{Q} 1}$ & Q2 & Q3 & Q4 \\
\hline \multicolumn{5}{|l|}{ Men } \\
\hline Hyperglycemia & 1.0 & $6.735(1.642-27.768)$ & 3.996(0.940-16.979) & $4.474(1.066-18.780)$ \\
\hline Hypertriglyceridemia & 1.0 & $1.815(0.713-4.621)$ & $3.229(1.268-8.222)$ & $3.418(1.358-8.602)$ \\
\hline Low HDL-C & 1.0 & $1.935(0.715-5.237)$ & $2.383(0.871-6.519)$ & 1.935(0.703-5.327) \\
\hline High blood pressure & 1.0 & $4.205(0.808-21.833)$ & $3.707(0.715-19.203)$ & 4.796(0.916-25.104) \\
\hline \multicolumn{5}{|l|}{ Pre-menopausal women } \\
\hline Hyperglycemia & 1.0 & $3.179(0.634-15.944)$ & $3.920(0.824-18.659)$ & $10.578(2.337-47.874)$ \\
\hline Hypertriglyceridemia & 1.0 & $4.441(0.927-21.277)$ & $9.962(2.280-43.535)$ & $17.657(4.132-75.460)$ \\
\hline Low HDL-C & 1.0 & $1.481(0.852-2.576)$ & $2.103(1.219-3.628)$ & $3.846(2.146-6.892)$ \\
\hline High blood pressure & 1.0 & $1.539(0.131-18.020)$ & 1.415(0.116-17.228) & $5.241(0.556-49.437)$ \\
\hline \multicolumn{5}{|l|}{ Post-menopausal women } \\
\hline Hyperglycemia & 1.0 & $3.396(1.104-10.447)$ & $4.205(1.408-12.560)$ & $3.867(1.304-11.466)$ \\
\hline Hypertriglyceridemia & 1.0 & 2.456(0.626-9.636) & $4.602(1.265-16.735)$ & $8.402(2.402-29.391)$ \\
\hline Low HDL-C & 1.0 & 2.293(0.860-6.110) & $1.944(0.749-5.047)$ & $1.751(0.680-4.509)$ \\
\hline High blood pressure & 1.0 & $1.502(0.326-6.919)$ & $1.489(0.354-6.257)$ & $1.607(0.408-6.330)$ \\
\hline
\end{tabular}

Odds ratios and $95 \%$ Cls adjusted for age, smoking status, drinking status, exercise status, sunshine time. Men $\left(\mathrm{Q} 1:<89.95 \mathrm{~cm}^{2}, \mathrm{Q} 2: 89.95-115.72 \mathrm{~cm}^{2}, \mathrm{Q} 3\right.$ : 115.72-140.46 cm², Q4: $\geq 140.46 \mathrm{~cm}^{2}$ ); Pre-menopausal women (Q1: $<53.15 \mathrm{~cm}^{2}, \mathrm{Q} 2: 53.15-66.18 \mathrm{~cm}^{2}, \mathrm{Q} 3: 66.18-84.47 \mathrm{~cm}^{2}$, Q4: $\left.\geq 84.47 \mathrm{~cm}^{2}\right)$; Post-menopausal women (Q1: $<71.55 \mathrm{~cm}^{2}$, Q2: $71.55-91.97 \mathrm{~cm}^{2}, \mathrm{Q} 3: 91.97-115.73 \mathrm{~cm}^{2}, \mathrm{Q} 4: \geq 115.73 \mathrm{~cm}^{2}$ ) 


\section{Abbreviations}

VFO: Visceral fat obesity; VFA: Visceral fat area; $25(\mathrm{OH}) \mathrm{D}_{3}$ : 25-hydroxyvitamin $\mathrm{D}_{3}$; BMI: Body mass index; WC: Waist circumference; WHR: Waist-to-hip ratio; FM: Fat mass; FFM: Free fat mass; PBF: Percentage body fat; DEXA: Dual-energy $x$-ray absorptiometry; MRI: Magnetic resonance imaging; $C$ : Computed tomography; BIA: Bioelectrical impedance analysis; FPG: Fasting plasma glucose; TC: Total cholesterol; TG: Triglycerides; LDL-c: Low-density lipoprotein cholesterol; HDLc: High-density lipoprotein cholesterol; HPLC: High-performance liquid chromatography; ANOVA: One-way analysis of variance.

\section{Competing interests}

The authors declare that they have no competing interests.

\section{Authors' contributions}

GH designed and conducted the study, provided direction for statistical analyses, drafted the final manuscript, and had primary responsibility for final content; $\mathrm{MZ}$ and PL analyzed the data and wrote the paper; $\mathrm{HC}, \mathrm{YZ}$, and XW conducted research and analyzed data; $W L$ and $Y Z$ provided the database for this study and coordinated the study. All authors read and approved the final manuscript.

\section{Acknowledgements}

We wish to thank all who participated in the study, the stuff at our Medical Check-up Center who assisted the study. This research was funded by the National Science and Technology Support Program (No. 2012BAI02B02) and National Natural Science Foundation of China (No. 81502809).

\section{Author details}

'Department of Nutrition and Food Science, School of Public Health, Tianjin Medical University, Tianjin 300070, China. ${ }^{2}$ Department of Rehabilitation and Sports Medicine, Tianjin Medical University, Tianjin 300070, China. ${ }^{3}$ Health Education and Guidance Center of Heping District, Tianjin 300040, China.

\section{Received: 6 July 2015 Accepted: 19 November 2015}

Published online: 25 November 2015

\section{References}

1. Holick MF, Binkley NC, Bischoff-Ferrari HA, Gordon CM, Hanley DA, Heaney $R P$, et al. Evaluation, treatment, and prevention of vitamin D deficiency: an Endocrine Society clinical practice guideline. J Clin Endocrinol Metab. 2011; 96:1911-30.

2. Samuel $L$, Borrell $L N$. The effect of body mass index on optimal vitamin D status in U.S. adults: the National Health and Nutrition Examination Survey 2001-2006. Ann Epidemiol. 2013;23:409-14.

3. Holick MF, Binkley NC, Bischoff-Ferrari HA, Gordon CM, Hanley DA, Heaney $\mathrm{RP}$, et al. Guidelines for preventing and treating vitamin D deficiency and insufficiency revisited. J Clin Endocrinol Metab. 2012;97:1153-8.

4. Holick MF. Vitamin D deficiency. N Engl J Med. 2007;357:266-81.

5. Lu L, Yu Z, Pan A, Hu FB, Franco OH, Li H, et al. Plasma 25-hydroxyvitamin $D$ concentration and metabolic syndrome among middle-aged and elderly Chinese individuals. Diabetes Care. 2009;32:1278-83.

6. Zhen D, Liu L, Guan C, Zhao N, Tang X. High prevalence of vitamin D deficiency among middle-aged and elderly individuals in northwestern China: Its relationship to osteoporosis and lifestyle factors. Bone. 2015;71:1-6.

7. Reis AF, Hauache OM, Velho G. Vitamin D endocrine system and the genetic susceptibility to diabetes, obesity and vascular disease. A review of evidence. Diabetes Metab. 2005;31:318-25.

8. Lagunova Z, Porojnicu AC, Vieth R, Lindberg FA, Hexeberg S, Moan J. Serum 25-hydroxyvitamin $D$ is a predictor of serum 1,25-dihydroxyvitamin $D$ in overweight and obese patients. J Nutr. 2011;141:112-7.

9. Rodríguez-Rodríguez E, Navia B, López-Sobaler AM, Ortega RM. Vitamin D in overweight/obese women and its relationship with dietetic and anthropometric variables. Obesity (Silver Spring). 2009;17:778-82.

10. Fox CS, Massaro JM, Hoffmann U, Pou KM, Maurovich-Horvat P, Liu CY, et al. Abdominal visceral and subcutaneous adipose tissue compartments: association with metabolic risl factors in the Framingham Heart Study. Circulation. 2007;116:39-48.

11. WHO. Obesity: preventing and managing the global epidemic. Report of a WHO consultation. World Health Organ Tech Rep Ser. 2000;894:i-xii. 1-253.
12. Cornier MA, Després JP, Davis N, Grossniklaus DA, Klein S, Lamarche B, et al. Assessing adiposity: a scientific statement from the American Heart Association. Circulation. 2011;124:1996-2019.

13. Xu L, Cheng X, Wang J, Cao Q, Sato T, Wang M, et al. Comparisons of body composition prediction accuracy: a study of 2 bioelectric impedance consumer devices in healthy Chinese persons using DXA and MRI as criteria methods. J Clin Densitom. 2011;14:458-64.

14. Kang SH, Cho KH, Park JW, Yoon KW, Do JY. Association of visceral fat area with chronic kidney disease and metabolic syndrome risk in the general population: analysis using multi-frequency bioimpedance. Kidney Blood Press Res. 2015;40:223-30.

15. Kotler DP, Burastero S, Wang J, Pierson Jr RN. Prediction of body cell mass, fat-free mass, and total body water with bioelectrical impedance analysis: effects of race, sex, and disease. Am J Clin Nutr. 1996;64(3 Suppl):489S-97S.

16. Hao Y, Ma X, Shen Y, Ni J, Luo Y, Xiao Y, et al. Associations of serum 25-hydroxyvitamin D3 levels with visceral adipose tissue in Chinese men with normal glucose tolerance. PLoS One. 2014;9:e86773.

17. Kuk JL, Lee S, Heymsfield SB, Ross R. Waist circumference and abdominal adipose tissue distribution: influence of age and sex. Am J Clin Nutr. 2005; 81:1330-4.

18. Gundberg CM, Looker AC, Nieman SD, Calvo MS. Patterns of osteocalcin and bone specific alkaline phosphatase by age, gender, and race or ethnicity. Bone. 2002;31:703-8.

19. Looker AC. Body fat and vitamin D status in black versus white women. J Clin Endocrinol Metab. 2005;90:635-40.

20. Shoji K, Maeda K, Nakamura T, Funahashi T, Matsuzawa Y, Shimomura I. Measurement of visceral fat by abdominal bioelectrical impedance analysis is beneficial in medical checkup. Obes Res Clin Pract. 2008;2:I-II.

21. Li R, Lu W, Jia J, Zhang S, Shi L, Li Y, et al. Relationships between indices of obesity and its cardiovascular comorbidities in a Chinese population. Cir J. 2008;72:937-8.

22. Kim TN, Park MS, Kim YJ, Lee EJ, Kim MK, Kim JM, et al. Association of low muscle mass and combined low muscle mass and visceral obesity with low cardiorespiratory fitness. PLoS One. 2014;9:e100118.

23. Holick MF. High prevalence of vitamin D inadequacy and implications for health. Mayo Clin Proc. 2006;81:353-73.

24. Earthman CP, Beckman LM, Masodkar K, Sibley SD. The link between obesity and low circulating 25-hydroxyvitamin D concentrations: considerations and implications. Int J Obes (Lond). 2012;36:387-96.

25. Shi H, Norman AW, Okamura WH, Sen A, Zemel MB. 1alpha, 25Dihydroxyvitamin D3 modulates human adipocyte metabolism via nongenomic action. FASEB J. 2001;15:2751-3.

26. Fassina G, Maragno I, Dorigo P, Contessa AR. Effect of vitamin D2 on hormone-stimulated lipolysis in vitro. Eur J Pharmacol. 1969;5:286-90.

27. Rodríguez-Rodríguez E, Navia-Lombán B, López-Sobaler AM, Ortega RM. Associations between abdominal fat and body mass index on vitamin $D$ status in a group of Spanish school children. Eur J Clin Nutr. 2010;64:461-7.

28. Nam GE, Kim do H, Cho KH, Park YG, Han KD, Choi YS, et al. Estimate of a predictive cut-off value for serum 25-hydroxyvitamin $D$ reflecting abdominal obesity in Korean adolescents. Nutr Res. 2012;32:395-402.

29. Hatfield DP, Sweeney KP, Lau J, Lichtenstein AH. Critical assessment of high-circulation print newspaper coverage of the Institute of Medicine report Dietary Reference Intakes for Calcium and Vitamin D. Public Health Nutr. 2014;17:1868-76.

30. Wortsman J, Matsuoka LY, Chen TC, Lu Z, Holick MF. Decreased bioavailability of vitamin D in obesity. Am J Clin Nutr. 2000;72:690-3.

31. Compston JE, Vedi S, Ledger JE, Webb A, Gazet JC, Pilkington TR. Vitamin D status and bone histomorphometry in gross obesity. Am J Clin Nutr. 1981; 34:2359-63.

32. McCarty MF, Thomas CA. PTH excess may promote weight gain by impeding catecholamine-induced lipolysis-implications for the impact of calcium, vitamin D, and alcohol on body weight. Med Hypotheses. 2003;61:535-42.

33. Sneve M, Figenschau $Y$, Jorde R. Supplementation with cholecalciferol does not result in weight reduction in overweight and obese subjects. Eur J Endocrinol. 2008;159:675-84.

34. Zittermann A, Frisch S, Berthold HK, Götting C, Kuhn J, Kleesiek K, et al, Vitamin D supplementation enhances the beneficial effects of weight loss on cardiovascular disease risk markers. Am J Clin Nutr. 2009;89:1321-7.

35. Salehpour A, Shidfar F, Hosseinpanah F, Vafa M, Razaghi M, Hoshiarrad A, et al. Vitamin D3 and the risk of CVD in overweight and obese women: a randomized controlled trial. Br J Nutr. 2012;108:1866-73. 
36. Drincic AT, Armas LA, Van Diest EE, Heaney RP. Volumetric dilution, rather than sequestration best explains the low vitamin D status of obesity. Obesity (Silver Spring). 2012;20:1444-8.

37. Vimaleswaran KS, Berry DJ, Lu C, Tikkanen E, Pilz S, Hiraki LT, et al. Causal relationship between obesity and vitamin D status: bi-directional Mendelian randomization analysis of multiple cohorts. Plos Med. 2013;10:e1001383.

38. Hannemann A, Thuesen BH, Friedrich N, Völzke H, Steveling A, Ittermann T, et al. Adiposity measures and vitamin D concentrations in Northeast Germany and Denmark. Nutr Metab (Lond). 2015;12:24.

39. Holick MF, Siris ES, Binkley N, Beard MK, Khan A, Katzer JT, et al. Prevalence of Vitamin D inadequacy among postmenopausal North American women receiving osteoporosis therapy. J Clin Endocrinol Metab. 2005;90:3215-24.

40. Isaia G, Giorgino R, Rini GB, Bevilacqua M, Maugeri D, Adami S. Prevalence of hypovitaminosis $D$ in elderly women in Italy: clinical consequences and risk factors. Osteoporosis Int. 2003;14:577-82.

41. Lips P, Duong T, Oleksik A, Black D, Cummings S, Cox D, et al. A global study of vitamin D status and parathyroid function in postmenopausal women with osteoporosis: baseline data from the multiple outcomes of raloxifene evaluation clinical trial. J Clin Endocrinol Metab. 2001;86:1212-21.

42. Lim SK, Kung AW, Sompongse S, Soontrapa S, Tsai KS. Vitamin D inadequacy in postmenopausal women in Eastern Asia. Curr Med Res Opin. 2008;24:99-106.

43. Yin $X$, Sun $Q$, Zhang $X$, Lu Y, Sun C, Cui Y, et al. Serum $25(\mathrm{OH})$ D is inversely associated with metabolic syndrome risk profile among urban middle-aged Chinese population. Nutr J. 2012;11:68.

44. Benetos A, Rudnichi A, Safar M, Guize L. Pulse pressure and cardiovascular mortality in normotensive and hypertensive subjects. Hypertension. 1998;32: $560-4$

45. Yoon H, Kim GS. The association of Vitamin D and Pulse pressure in Korean Adults: Korea National Health and Nutrition Survey, 2010. J Korea Acad Industr Coop Soc. 2013;14:2735-42.

46. Gasowski J, Fagard RH, Staessen JA, Grodzicki T, Pocock S, Boutitie F, et al. Pulsatile blood pressure component as predictor of mortality in hypertension: a meta-analysis of clinical trial control groups. J Hypertens. 2002;20:145-51.

47. Franklin SS, Khan SA, Wong ND, Larson MG, Levy D. Is pulse pressure useful in predicting risk for coronary heart disease? The Framingham heart study. Circulation. 1999;100:354-60.

48. Baker JF, Mehta NN, Baker DG, Toedter G, Shults J, Von Feldt JM, et al. Vitamin D, metabolic dyslipidemia, and metabolic syndrome in rheumatoid arthritis. Am J Med. 2012;125:1036.e9-1036.e15.

49. Kim J. Association between serum vitamin D, parathyroid hormone and metabolic syndrome in middle-aged and older Korean adults. Eur J Clin Nutr. 2015:69:425-30.

50. Kim MK, II Kang M, Won Oh K, Kwon HS, Lee JH, Lee WC, et al. The association of serum vitamin D level with presence of metabolic syndrome and hypertension in middle-aged Korean subjects. Clin Endocrinol (Oxf). 2010;73:330-8.

51. Yoon H, Kim GS, Kim SG, Moon AE. The relationship between metabolic syndrome and increase of metabolic syndrome score and serum vitamin Dlevels in Korean adults: 2012 Korean National Health and Nutrition Examination Survey. J Clin Biochem Nutr. 2015;57:82-7.

52. Forouhi NG, Luan J, Cooper A, Boucher BJ, Wareham NJ. Baseline serum 25-hydroxy vitamin d is predictive of future glycemic status and insulin resistance: the Medical Research Council Ely Prospective Study 1990-2000. Diabetes. 2008;57:2619-25.

53. Zhou QG, Hou FF, Guo ZJ, Liang M, Wang GB, Zhang X. 1, 25Dihydroxyvitamin $D$ improved the free fatty-acid-induced insulin resistance in cultured C2C12 cells. Diabetes Metab Res Rev. 2008:24:459-64.

54. Goodpaster BH, Krishnaswami S, Resnick H, Kelley DE, Haggerty C, Harris TB, et al. Association between regional adipose tissue distribution and both type 2 diabetes and impaired glucose tolerance in elderly men and women. Diabetes Care. 2003:26:372-9.

55. Hayashi T, Boyko EJ, Leonetti DL, McNeely MJ, Newell-Morris L, Kahn SE, et al. Visceral adiposity is an independent predictor of incident hypertension in Japanese Americans. Ann Intern Med. 2004;140:992-1000.

56. Nagaretani $H$, Nakamura T, Funahashi $T$, Kotani K, Miyanaga M, Tokunaga $K$ et al. Visceral fat is a major contributor for multiple risk factor clustering in Japanese men with impaired glucose tolerance. Diabetes Care. 2001:24:2127-33.

57. Carr DB, Utzschneider KM, Hull RL, Kodama K, Retzlaff BM, Brunzell J, et al. Intra-abdominal fat is a major determinant of the national cholesterol education program adult treatment panel III criteria for the metabolic syndrome. Diabetes. 2004;3:2087-94.

58. Hyun YJ, Kim OY, Jang Y, Ha JW, Chae JS, Kim JY, et al. Evaluation of metabolic syndrome risk in Korean premenopausal women: not waist circumference but visceral fat. Circ J. 2008;72:1308-15.

59. Seo JA, Kim BG, Cho H, Kim HS, Park J, Baik SH, et al. The cutoff values of visceral fat area and waist circumference for identifying subjects at risk for metabolic syndrome in elderly Korean: Ansan Geriatric (AGE) cohort study. BMC Public Health. 2009:9:443.

\section{Submit your next manuscript to BioMed Central and we will help you at every step:}

- We accept pre-submission inquiries

- Our selector tool helps you to find the most relevant journal

- We provide round the clock customer support

- Convenient online submission

- Thorough peer review

- Inclusion in PubMed and all major indexing services

- Maximum visibility for your research

Submit your manuscript at www.biomedcentral.com/submit 